\title{
Incorporating Customer Service Expectations In The Restaurant Industry: The Guide To Survival
}

M.C. Cant, Ph.D., University of South Africa, South Africa

C. Erdis, MCom, University of South Africa, South Africa

\begin{abstract}
With the remarkable growth and economic contributions of the services industry, companies are finding that they need to focus on service to keep up with rising customer expectations and to compete effectively. Thus excellent customer service in a restaurant has the potential of differentiating the restaurant from competing ones and could lead to creating a competitive advantage. Thus, if a restaurant becomes well known for its superior customer service, this can be used as a way of outmanoeuvring competing restaurants. This article examines customer service in selected restaurants in the Tshwane area. It is aimed at establishing criteria for excellent customer service in restaurants, which can serve as the basis for building good relationships with customers. An empirical study was conducted to namely to investigate customer service in selected restaurants in the Tshwane Area, with the aim to establish criteria for excellent customer service as a benchmark for establishing relationships with customers, by means of an exploratory study. A self-administered survey was conducted whereby questionnaires were handed to restaurant patrons with the restaurant bill folder. Based on the research results, criteria were developed for excellent customer service which can be used as a benchmark for establishing relationships with customers, by providing customer satisfaction, which leads to customer retention, loyalty and ultimately profitability for an organisation.
\end{abstract}

Keywords: Customer Service; Service Expectations; Criteria; Service Levels; Service Quality; Servicescape; Attitude; Price

\section{INTRODUCTION}

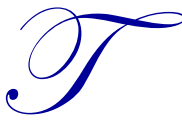

he success of service organisations such as restaurants can to a large extent be attributed to the relationship that exists between the restaurant and the customer. This is maintained by Brink and Berndt (2008:55), who state that "high-quality customer service is key to improving relationships with customers, and an enhanced relationship with one's customers can ultimately lead to greater customer retention, customer loyalty and more importantly, profitability". The importance of this relationship is further underscored by the fact that during difficult economic times customers tend to be more selective in the restaurant they choose to frequent (Erdis 2010:32). More often than not the restaurant that best meets the needs of the customer is the one which will survive.

The relationship that develops between restaurant patron and restaurant, and the selection of a restaurant is in turn affected by several criteria used by customers, one of which is the quality of service provided by the restaurant, and how this service is experienced by the customer.

It can be argued that restaurant owners that are not aware of, and do not incorporate the criteria regarding the quality of service as expected by customers, will be less successful than those who do. 


\section{DISCUSSION}

The research of Heskett, Jones, Loveman, Sasser and Schlesinger (2008:120), on the analyses of successful service organisations, shows that there are "relationships between profitability; customer loyalty; employee satisfaction; loyalty; and productivity". Therefore, an enhanced relationship with customers can in turn lead to greater customer retention, customer loyalty and ultimately profitability (Brink \& Berndt 2008:55).

Restaurant owners are not always aware of the aspects which are important to customers in terms of service, which may result in them losing the patronage of these customers.

This article therefore aims to establish criteria used by customers in order to provide superior customer service in restaurants. These criteria could be used to train restaurant staff such as waiters and receptionists and others, in the rendering of excellent customer service. It is imperative that the criteria used by customers to evaluate the level of customer service provided by the restaurant owner, be known by the restaurant owner and be incorporated in its offering to customers.

Service providers such as restaurants, who provide expert service, effectively handle complaints and generally show professionalism, tend to have more satisfied customers (Pressey and Mathews 2000:10). A high standard of customer service will therefore result in customer satisfaction, thereby enabling the restaurant to initiate the establishment of long-term relationships with patrons. Xu, Goedegebuure and Heijden (2006:79-87) maintain that investigation of various service industries demonstrated that loyal customers generate more revenue over more years, and that the cost of maintaining customers is often lower than the promotion cost needed to acquire new customers. Restaurants, however, cannot provide adequate service levels to their customers and therefore establish relationships with their customers, if they are not aware of the criteria used by customers to evaluate their service.

This article will identify these criteria which are regarded as important deciding factors to customers when patronising a restaurant, and how these criteria can be incorporated in the total service offering of the restaurant.

\section{METHOD}

A quantitative study was conducted by means of an experience survey. This survey method was selected in order to obtain information on customer service in selected restaurants in Tshwane, as well as the criteria used by customer's when selecting restaurants to patronise.

A self-administered questionnaire was used in order to collect the primary data. This was used as many service organisations use this method including airlines, hotels and restaurants, where a brief questionnaire is provided to determine certain aspects such as the customer's perception of the service received, such as in the case of this study.

As self-administered interviews were decided on in this study, a questionnaire was designed to gather the exploratory data. In the questionnaire, closed-ended as well as open-ended questions were used. The open-ended questions included non-comparative scales such as the Likert scale, which shows a series of attitudes toward an object, which are given numerical values ranging from favourable to unfavourable (McDaniel \& Gates 2003:274).

The elements for this study were drawn by means of convenience sampling, which is a non-probability sampling method and were drawn from a list of restaurants in the Tshwane area of Gauteng, South Africa. was used as a sample frame. The choice of convenience sampling and restaurants in the East of Tshwane was based on facilitation of the research and on the LSM profile of the restaurant patrons of this area, many of which have an average income of more than R18 000 (Cant, Strydom, Jooste \& Du Plessis 2006:115; Anon 2008:41). A sample size of 300 respondents was selected, with 30 respondents being selected in each of the 10 restaurant to be included in the study. As this was an exploratory study, the sample size was deemed adequate.

The computer Software package SPSS 11.0 was used to carry out all analysis. After validating and editing each questionnaire, the data was directly entered into SPSS. 
Although an exploratory study was conducted and therefore descriptive statistics adequate for the purposes of this study, it was decided by the researcher to conduct certain significance tests as well due to the fact that a large number of respondents (namely 292) completed the questionnaire. The following significant tests were therefore used in this study:

- Chi-Square. A chi-square test is used when a set of observed frequencies are compared to a set of theoretical (expected) frequencies (Tustin, Lighelm, Martins \& Van Wyk 2005:609).

- $\quad$ Analysis of variance (ANOVA). This test is used for examining the differences in the mean values of the dependant variable associated with the effect of the controlled independent variables (Malhotra 2004:469). The ANOVA test calculates both an F-value and a p-value. A p-value of 0,05 is considered significant.

- $\quad$ Correlation analysis. Correlation analysis is the analysis of the degree to which changes in one variable are associated with changes in another (McDaniel \& Gates 2003:448).

\section{RESULTS}

Respondents were asked to rate certain factors of the exterior, interior, service and food of the restaurants on a scale of 1 to 5, where 1 represented "Poor" and 5 represented "Very good".

These factors form part of the servicescape of a restaurant, which is the physical evidence that organisations need to provide the customer as cues for its service quality, as customers often rely on tangible cues or physical evidence to evaluate service (Zeithaml et al 2009:313; Brink \& Berndt 2008:83).

- $\quad$ Exterior of the restaurant

Questions were included to test the exterior factors of the servicescape such as the signage, parking, security, cleanliness and the attractiveness of the restaurant. Cleanliness and attractiveness are the aspects of the exterior that were rated the highest by the respondents, while signage and parking received the lowest relative ratings, as can be seen from figure 1 .

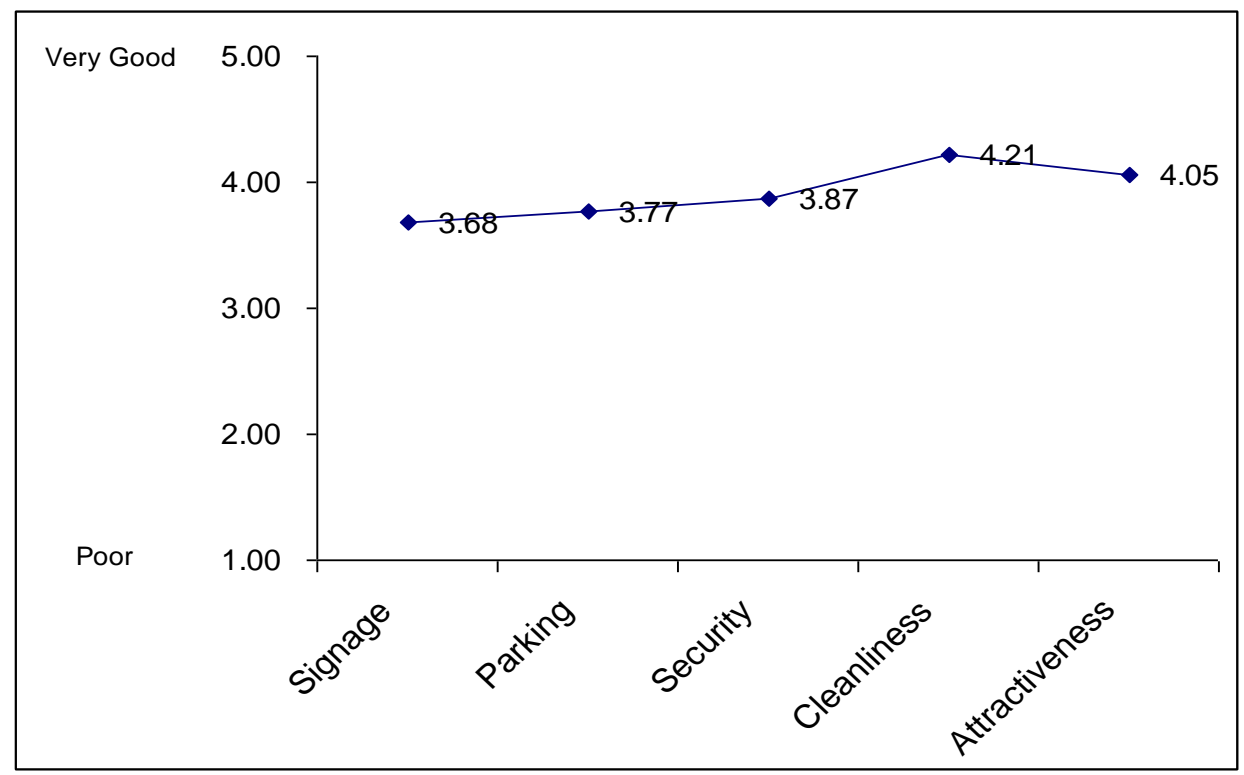

Figure 1: Mean scores of the ratings of the factors of the exterior $(288 \geq n \geq 290)$ 
- Interior of the restaurant

Factors of the interior rated by respondents included atmosphere, décor, lighting, cleanliness of the eating area, comfortability of the furniture and cleanliness of the bathrooms and are illustrated in figure 2.

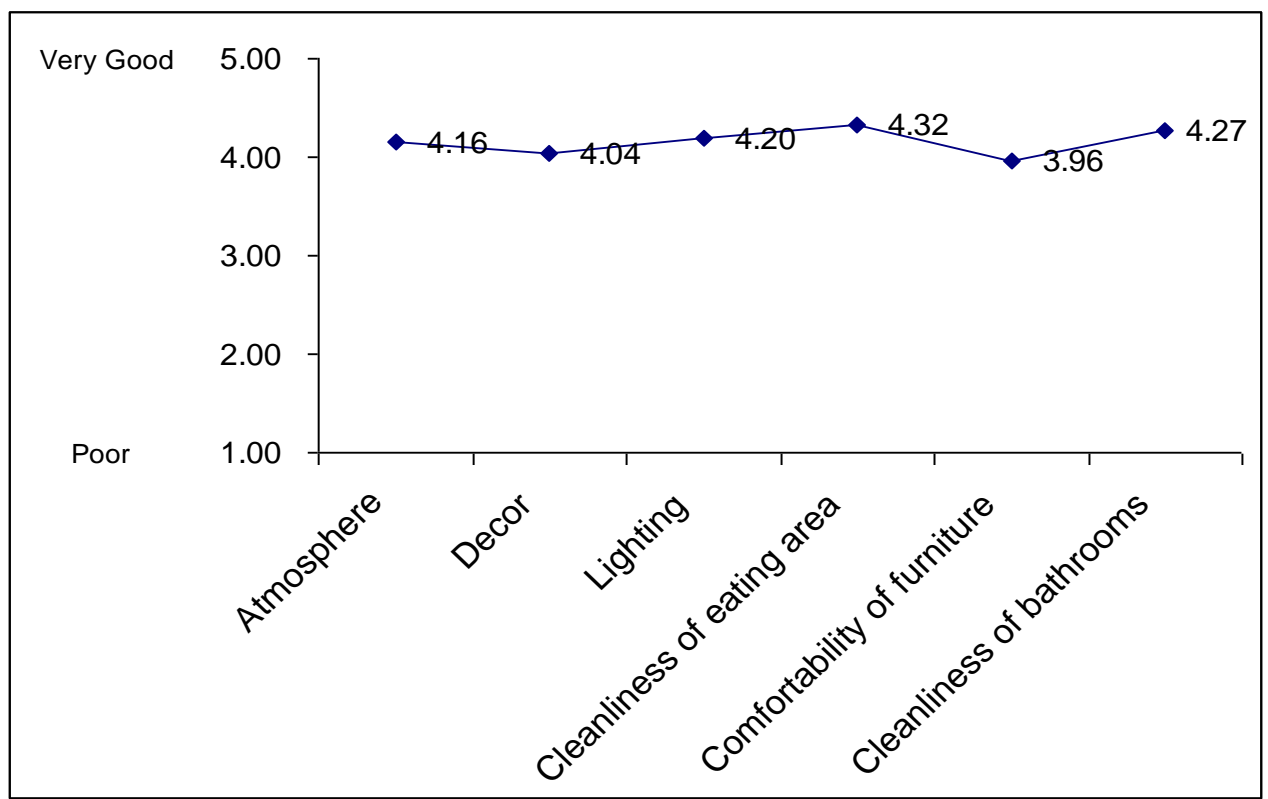

Figure 2: Mean scores of the ratings of the factors of the Interior (288 $\geq \mathbf{n} \geq 290)$

Once again, cleanliness rated best overall; both the cleanliness of the eating area and the bathrooms were rated very well. Atmosphere, décor and lighting were also rated well, while the furniture at the various restaurants was rated as not being particularly comfortable, receiving a relatively low rating.

- $\quad$ Service levels

The service encounter or "moment of truth" literally means that this is the time and place when and where the organisation has the opportunity to demonstrate the quality of its services to the customer (Brink, Machado, Strydom \& Cant 2001:19). It is in these encounters that customers receive a "snapshot" of the organisation's service quality, and each encounter contributes to the customer's overall satisfaction and willingness to do business with the organisation again.

A question was therefore included to test the importance of the fundamental principle of the "moment of truth" in the restaurants researched. The researcher therefore decided to include the following service aspects to be rated by the respondents as each are important events or standards in a restaurant environment:

- $\quad$ Professionalism

- $\quad$ Friendliness

- $\quad$ Speed of service

- $\quad$ Product knowledge

- Handling of special requests/orders

- Reservation details recorded correctly

- $\quad$ Time waited to be seated 
Service factors were rated consistently high, all achieving above 4 out of 5 (as can be seen in figure 3 ). The relative weaker rated areas are professionalism and speed of service. Restaurant staff were rated as generally friendly, knowledgeable and willing to help (a score of 4.19 was achieved for both). With such consistently high scores, it can therefore be deduced that the respondents were generally satisfied with the service levels encountered.

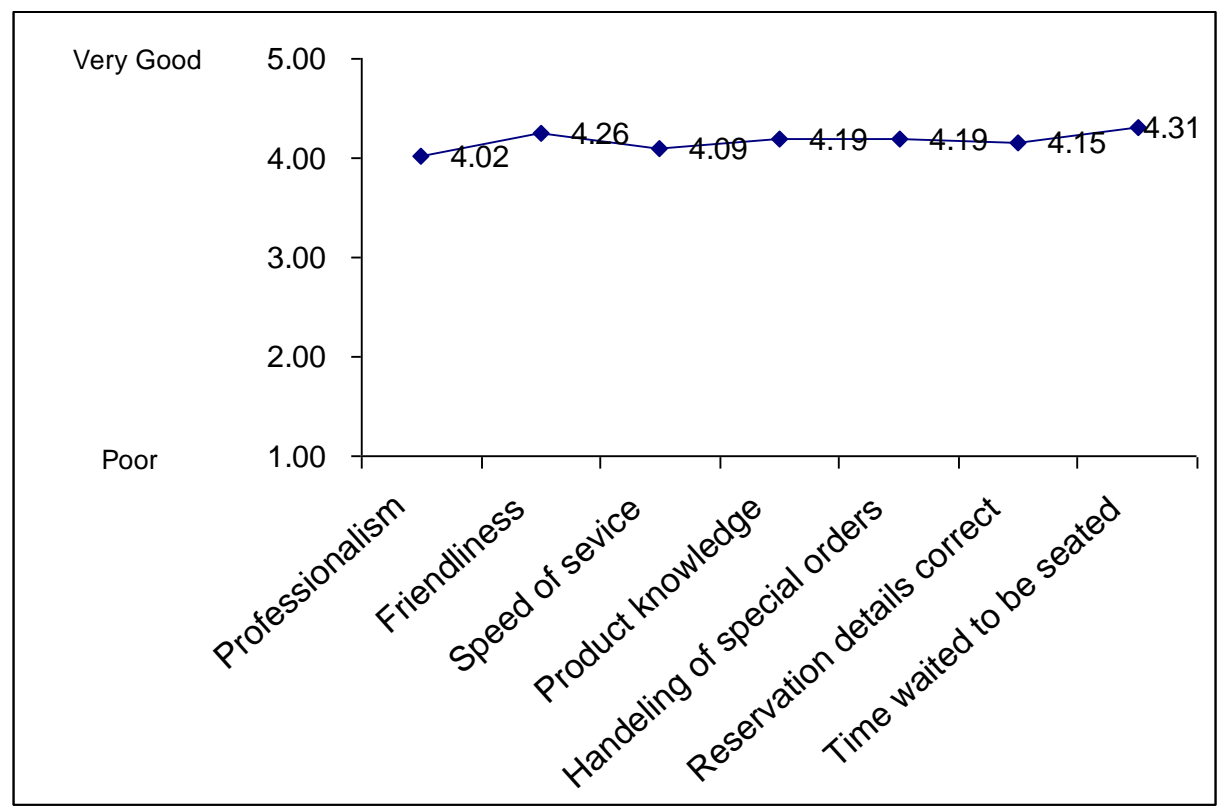

Figure 3: Mean scores of the ratings of the factors of the service $(278 \geq \mathbf{n} \geq 292)$

- Quality of food served

In order to determine the influence of the customer's interaction with the service provider's products, the researcher had included a question on the quality of the food served. The three food quality-related factors rated (presentation, menu variety and correctness of the order) all received consistently high scores of above 4 out of 5.

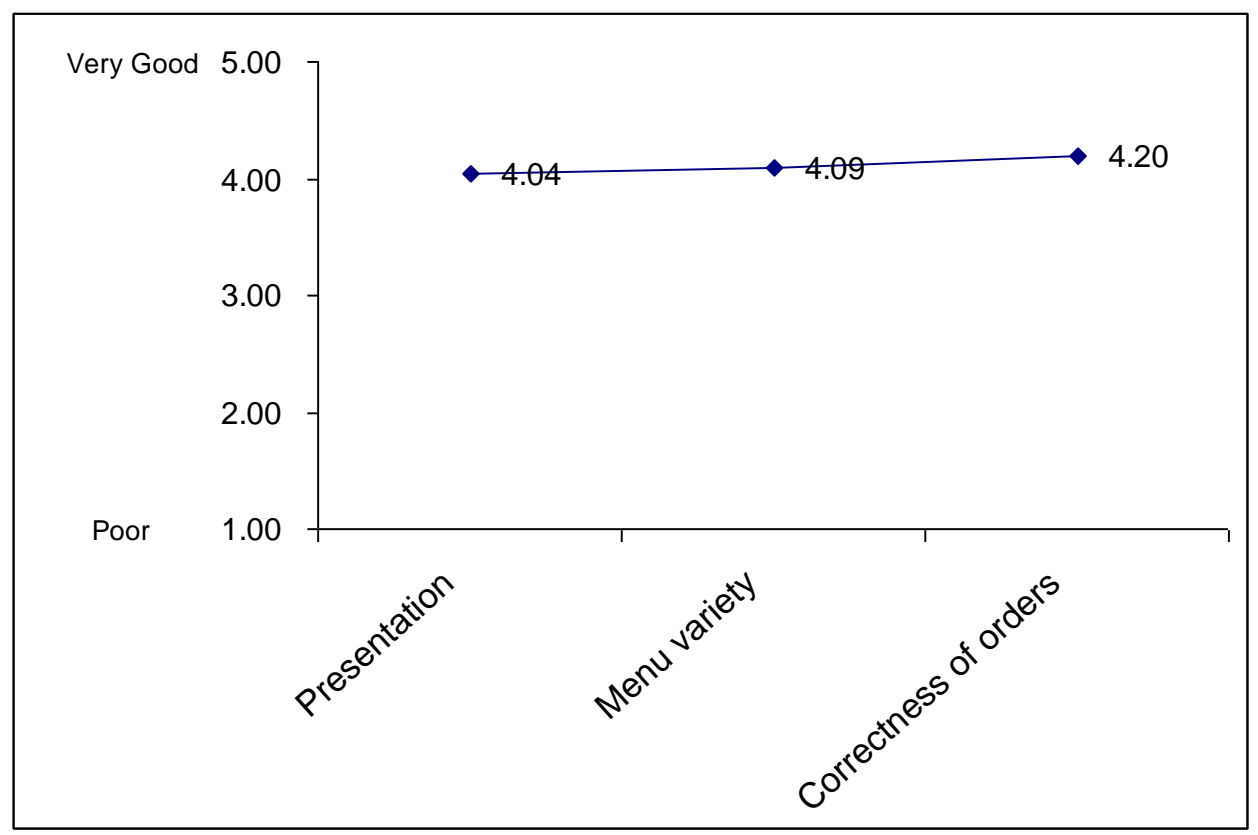

Figure 4: Mean scores of the ratings of the food related aspects $(283 \geq n \geq 282)$ 
As can be seen above, correctness of orders received the highest rating (4.20), followed by menu variety (4.09) and the presentation of food (4.04). It can therefore be deduced that the respondents who completed the questionnaire had a favourable interaction with the service provider's products.

- $\quad$ Overall value for money

As an overall measure of quality of the restaurant, respondents were asked to rate the overall value for money that the restaurant offers on a scale of $1-5$, where 1 is poor value for money and 5 is very good value for money.

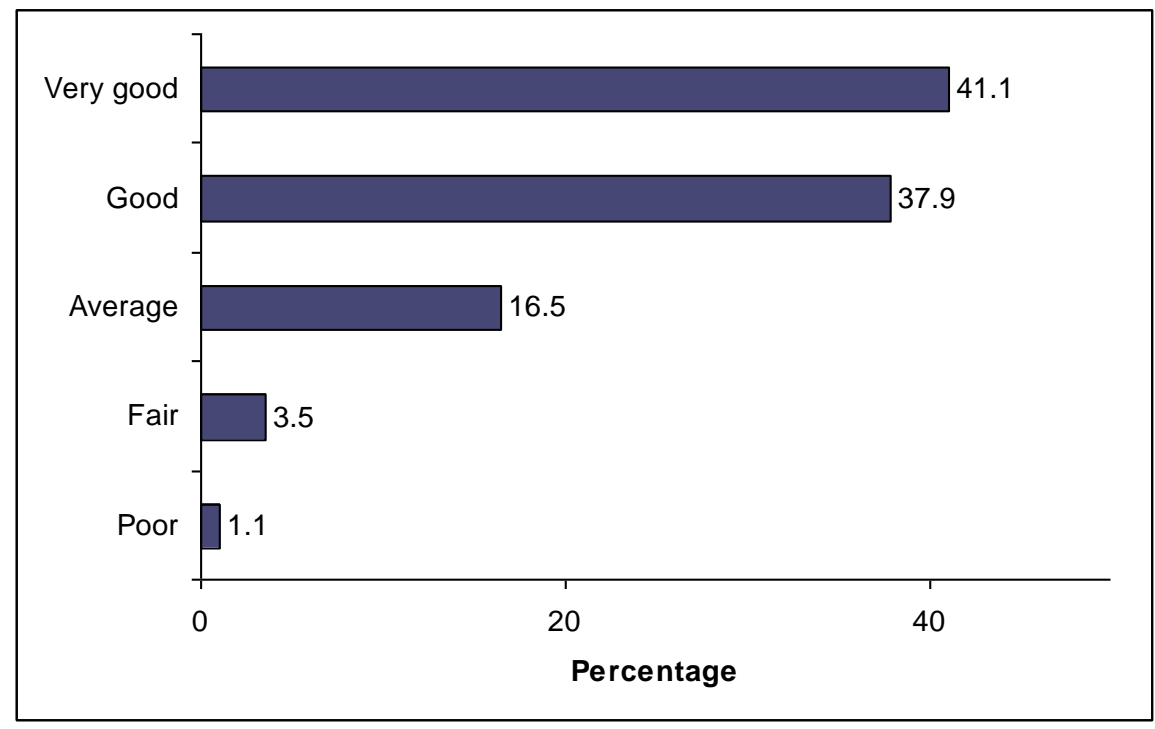

Figure 5: Overall value for money $(n=285)$

As illustrated in figure 5 above, the findings showed that the most respondents consider the restaurant to be very good value for money (41.1\%) or at least good value for money (37.9). Only $1.1 \%$ rated the restaurant as being poor value for money. It can therefore be deduced that customers who view a restaurant as providing good value for money will be more satisfied with the overall service levels than those than do not. This is in line with statements made by FEDHASA's Chairperson Phillip Couvaras and Vice-Chairperson Rey Franco, where they state that patrons are now more careful when selecting dining options and decisions tend to be based on genuine value for money and friendly, efficient service (Anon 2009:1).

- $\quad$ Attitudes towards the restaurants

In this section, the findings regarding the attitudes of the respondents towards the restaurant in general as well as its pricing will be discussed.

\section{General attitudes}

A question was included to test the fundamental principles behind the relationship ladder of loyalty by Christopher, Payne and Ballantyne (2002:48), in that there are a number of identifiable stages in the development of a long-term customer relationship. Hence the inclusion of a number of statements related to each step of the ladder. The statements are related to the steps in the ladder in the following way: 


$-\quad$ Statement 1 - I would strongly recommend this restaurant to others (advocate)
-
Statement 2 - This is not the only restaurant I frequently visit (supporter)
Statement 3 - I have visited this restaurant before, but my experiences have not always
been positive, but I will return to this restaurant (client)
- $\quad$ Statement 4 - I have visited this restaurant before but will not return again (author's own statement)
Statement 5 - This is the first time that I have visited this restaurant (purchaser)
Statement 6 - I would not have chosen this restaurant of my own accord (prospect)

The respondents had to evaluate these statements about the restaurant using a 0 - to-10 rating scale with 10 being the most positive value.

The findings (summarised in table 1) indicate that most restaurant users would strongly recommend the restaurant to someone with a mean score of 8.23 out of 10 , while on average only 2.82 of respondents indicated that they have visited the restaurant before but would not visit it again.

Table 1: Descriptive statistics on attitude statements

\begin{tabular}{|c|c|c|c|}
\hline & $\mathbf{N}$ & Mean & Std. Deviation \\
\hline I strongly recommend this restaurant & 292 & 8.23 & 1.995 \\
\hline This is not the only restaurant I frequently visit & 286 & 6.80 & 2.553 \\
\hline I have visited this restaurant before my experience wasn't always positive but I will return & 284 & 5.30 & 3.248 \\
\hline I have visited this restaurant before but will not return again & 280 & 2.82 & 2.794 \\
\hline This is the first time I have visited this restaurant & 281 & 3.97 & 3.500 \\
\hline I would not have chosen this restaurant of my own accord & 280 & 4.15 & 3.091 \\
\hline
\end{tabular}

Respondents awarded a relatively low score of 4.15 out of 10 on average to the statement "I would not have chosen this restaurant of my own accord", while 3.97 on average indicated that it was the first time they had visited the restaurant. On average 4.15 of the respondents indicated that they would not have chosen the restaurant in question on their own.

From the above results, it is clear that the majority of respondents are in fact advocates (with a mean score of 8.23) and supporters (with a mean score of 6.80) when compared to the relationship ladder of loyalty as identified by Christopher et al (2002:48). The statement that the researcher included ("I have visited this restaurant before but will not return again") obtained the lowest mean score of 2.82. One may thus conclude the majority of respondents are satisfied and that this could serve as the basis for a relationship.

Attitude towards price

In addition to testing respondent's general attitudes towards the restaurant, their attitude toward price as a driver of restaurant choice was also examined by means of a five point rating scale. The findings are illustrated in Figure 6 below.

Price appears to be a very important driver of restaurant choice with $37.1 \%$ of respondents indicating that it is very important and an additional $30.1 \%$ of respondents indicating that it is rather important. $24.8 \%$ of the respondents interviewed indicated that price is of average importance and $4.5 \%$ indicated that it was fairly important.

Only $3.5 \%$ of the respondents indicated that price was not an important driver of restaurant choice. This is to be expected with the recent worldwide economic downturn, pull-back in consumer spending and levels of domestic expenditure dropping significantly in the second quarter of 2009 (Anon 2009:1). 


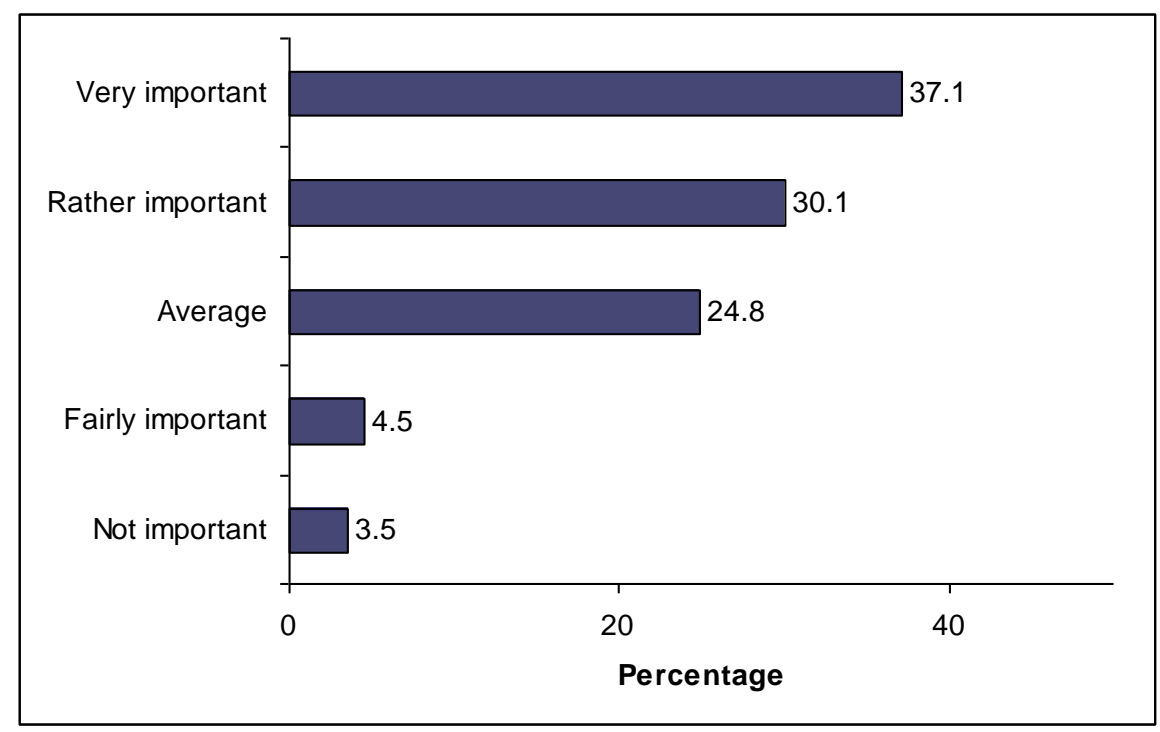

Figure 6: Importance of price in deciding on a restaurant $(n=286)$

It was also found that respondents of all ages, language groups and family compositions are equally price sensitive and no significant differences exist between these groups:

- $\quad$ Correlation between age and price $: \mathrm{p}=0.245$

- $\quad$ Anova test between language and price: $p=0.984$

- $\quad$ Anova test between family composition and price; $p=0.074$

\section{DISCUSSION AND CONCLUSION}

The aim of this article was to establish restaurant patron's criteria for selecting restaurants as many restaurant owners are faced with the problem of how to provide high levels of customer service resulting in customer satisfaction which can be used as a basis for establishing relationships with these customers. This would ultimately enhance customer retention and loyalty, and ultimate greater profitability and survival. Conclusions regarding the respondents, as well as their attitudes towards the restaurant in terms of various restaurant attributes, the level of service received and attitudes towards price will be discussed next as an impetus for developing the criteria that restaurant patrons use in order to select restaurants.

In the survey, respondents were asked to rate exterior factors of the restaurants such as signage, parking, security, cleanliness and the attractiveness of the exterior. Cleanliness and attractiveness were the factors of the exterior that were rated the highest, while signage and parking received the lowest relative ratings.

Factors of the interior of the restaurants rated by respondents included atmosphere, décor, lighting, cleanliness of the eating area, comfortability of the furniture and cleanliness of the bathrooms. Once again, cleanliness rated best overall; both the cleanliness of the eating area and the bathrooms were rated very well. Atmosphere, décor and lighting were also rated well, while the furniture at the various restaurants was rated as not being particularly comfortable, receiving a relatively low rating. These factors investigated form part of the servicescape of the restaurant.

In order to ascertain the respondents overall satisfaction and willingness to do business with the organisation again, the researcher decided to include various service aspects such as friendliness, product knowledge and speed of service to be rated by the respondents, as each is an important event or standard in a restaurant environment. These aspects were included to test patron's experience of various important service encounters or "moments of truth". 
These service aspects were rated consistently high, all achieving above 4 out of 5 . The relative weaker rated areas are professionalism and speed of service. Staff were rated as generally friendly, knowledgeable and willing to help. With such consistently high scores, it can therefore be deduced that the respondents were generally satisfied with the service levels experienced. The three food quality related aspects rated (presentation, menu variety and correctness of the order) all received consistently high scores and it can therefore be deduced that the respondents who completed the questionnaire had a favourable interaction with the service provider's products and the various "moments of truth".

As an overall measure of quality of the restaurant, respondents were also asked to rate the overall value for money that the restaurant offers, and most respondents considered the restaurant to be very good value for money, with only $1.1 \%$ rated the restaurant as being poor value for money. It can therefore be deduced that customers who view a restaurant as providing good value for money will be more satisfied with the overall service levels than those that do not.

The following can be concluded from the attribute rating of the restaurants:

- Cleanliness, atmosphere, decór and lighting were aspects of the restaurants' servicescape that were rated the highest.
All of these factors would contribute to a patron visiting a restaurant again as cleanliness of the restaurant relates
directly to the perception of cleanliness and of the freshess of the food served..
Due to the fact that that the majority of patrons were visiting the restaurant in question for social reasons, the
restaurant's atmosphere, decór and lighting would have a large impact on how the patron would enjoy his/her visit to
the restaurant in question.
The various service aspects that were rated by the respondents, such as friendliness and product knowledge, were
consistently highly rated, and it can therefore be deduced that the respondents were generally satisfied with the service
levels encountered.
As the food quality related aspects rated all received consistently high scores it can therefore be deduced that the
respondents who had a favourable interaction with the service provider's products.
Customers who view a restaurant as providing good value for money will be more satisfied with the overall service
levels than those that do not.

In the next section of the questionnaire, the researcher included a number of statements related to each step of the relationship ladder of loyalty. From the results, it is clear that the majority of respondents are in fact advocates and supporters when compared to the relationship ladder of loyalty as identified by Christopher et al (2002:48). The statement that the author included ("I have visited this restaurant before but will not return again") obtained the lowest mean score of 2.82. One may thus conclude that the majority of respondents were satisfied with the level of service received, and that this level of satisfaction could serve as a basis for establishing relationships with these patrons.

Price also appears to be an important driver of restaurant choice, with only $3.5 \%$ of the respondents indicating that price was not an important driver of restaurant choice.

The following can be concluded from the attitudes towards the restaurants:

- $\quad$ That the majority of respondents are satisfied with the level of service received. The majority of respondents selected statements that indicated that they were advocates and supporters of the restaurant in question, which can be inferred from the options they selected

- $\quad$ Price is a very important driver in the choice of restaurant

The survey results reveal that there are certain criteria that a restaurant should fulfill in order to successfully establish relationships with its customers in the Eastern Suburbs of Tshwane. These criteria can be used to benchmark a particular restaurant towards providing satisfactory levels of customer service, and are listed in Exhibit 1: 
Exhibit 1: Criteria for excellent customer service in restaurants in the East of Tshwane

\begin{tabular}{|l|}
\hline Successful Restaurants: \\
\hline - \\
Eater for children in areas such as menu selection and baby-care facilities \\
- \\
Ehoure that English and African-language speakers are catered for, and that management, reception-staff and waitrons \\
Ensure that patrons feel relaxed and comfortable enough at the particular restaurant to socialise there, which is their \\
main reason for eating out \\
Focus on cleanliness, atmosphere, decór and lighting. All of these factors contribute to a patron visiting a restaurant \\
again \\
Ensure that patrons have a favourable interaction with the restaurant's products \\
Ensure that patrons have a positive experience of various important "moments of truth" \\
Provide good value for money in terms of the food served \\
Charge prices that patrons are willing to pay as price is a very important driver in the choice of restaurant \\
- $\quad$ Satisfy older respondents who are more critical of aspects of the interior and exterior and some of the service attributes \\
of the restaurants in question.
\end{tabular}

Although the above list is by no means a complete checklist of the criteria for excellent customer service in restaurants, restaurants in the East of the Tshwane Area should evaluate themselves against these points.

This will hopefully provide a benchmark in guiding them towards providing better customer service, higher customer satisfaction and therefore establishing relationships with their customers.

\section{AUTHOR INFORMATION}

Prof. Cant is a professor as well as the HOD at the Department of Marketing and Retail, Unisa. His research interests include marketing, retail and small businesses. E-mail: cantmc@ unisa.ac.za, 012 429-4456

Mrs Erdis is a lecturer in the Department of Marketing and Retail at Unisa. She holds a MCom degree and her research interests include retail, CRM and customer service. E-mail: erdisc@unisa.ac.za, 012 429-4615, (Corresponding author)

\section{REFERENCES}

1. Anon. "City of Tshwane Household Survey 2008". http://www.tshwane.gov.za/documents/cityplanning/CoT_HouseholdSurvey2008.pd. Date accessed: 27 November 2009.

2. Anon. "FEDHASA Cape seeks to offer balanced perspective on restaurant closures". Hyperlink. http//:www.travelwires.com/wp/2009/06/fedhasa-seeks-to-offer-balanced-perspective-on-restaurantclosures/. Date accessed: 22 September 2009.

3. Brink, A \& Berndt, A (eds). 2008. Relationship marketing and customer relationship management and customer service. Landsdowne: Juta.

4. Brink, A, Machado, R, Strydom, JW \& Cant, MC. 2001. University of South Africa. Centre for Business Management. Study guide for CRM 101-H. Pretoria.

5. Christopher, M, Payne, A and Ballantyne, D. 2002. Relationship marketing: creating stakeholder value. Oxford: Butterworth-Heinemann.

6. Cant, MC, Strydom, JW, Jooste, CJ \& Du Plessis, PJ (eds.). 2006. Marketing management. 5th edition. Kenwyn: Juta.

7. Erdis, C. 2010. Investigating customer service in selected restaurants in Tshwane - an exploratory study. Published M Comm. Dissertation, February 2010: University of South Africa.

8. Heskett, JL, Jones, TO, Loveman, GW, Sasser, WE \& Schlesinger, LA. 2008. Putting the service profit chain to work. Harvard Business Review, July - August 2008, p. 118-132.

9. Malhotra, NK. 2004. Marketing research: an applied orientation. $4^{\text {th }}$ edition. Upper Saddle River: Prentice Hall. 
10. McDaniel, C \& Gates, R. 2003. Marketing research essentials. $4^{\text {th }}$ edition. Cincinnati, Ohio: SouthWestern College.

11. Pressey, AD \& Mathews, BP. 2000. Barriers to relationship marketing in consumer retailing. Journal of services marketing, 14(3): 13-27.

12. Tustin, DH, Ligtelm, AA, Martins, JH, \& Van Wyk, H de J. 2005. Marketing research in practice. Pretoria: Unisa Press.

13. Xu, Y, Goedebuure, R \& Van der Heiden, B. 2006. Customer perception, customer satisfaction and customer loyalty within the Chinese securities business: towards a mediation model for predicting customer behaviour. Journal of Relationship Marketing, 5(4): 79-87.

14. Zeithaml, VA, Bitner, MJ \& Gremler, DD. 2009. Services marketing - integrating consumer focus across the firm. New York: McGraw-Hill. 
NOTES 